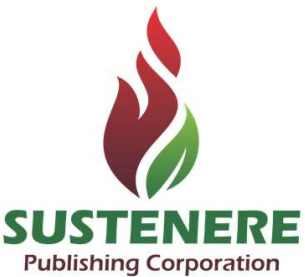

Publishing Corporation

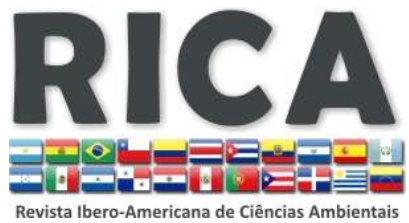

Journals Homepage:

www.sustenere.co/journals

\section{A EFICÁCIA DA AVALIAÇÃO DE IMPACTOS AMBIENTAIS NO BRASIL}

\section{RESUMO}

A Avaliação de Impactos Ambientais (AIA) foi instituída pela Política Nacional do Meio Ambiente (Lei 6.938/1981) como um dos instrumentos de gestão ambiental destinados à preservação, melhoria e manutenção da qualidade ambiental do país. Após mais de 30 anos de sua previsão no ordenamento jurídico brasileiro, faz-se necessário avaliar os resultados obtidos. Este trabalho examinou a eficácia da AIA, isto é, se o instrumento alcançou o objetivo para o qual foi criado. A pesquisa foi exploratória, delineada por métodos bibliográficos e documentais, e baseada na triangulação de três dimensões analíticas: 1) objetivos primordiais da AIA; 2) implementação e execução do instrumento; e 3) sua situação atual e perspectivas no Brasil. Concluiu-se que, embora tenha produzido efeitos positivos, o instrumento ainda não tem adequadamente prevenido o dano ambiental decorrente de quaisquer propostas desenvolvimentistas que tenham o potencial para tanto, como era o objetivo primordial. Os motivos dessa reduzida eficácia são explicados pela falta de um quadro legal e institucional que possibilite análises da viabilidade ambiental de propostas que independem do processo de licenciamento ambiental e pelas fragilidades nos procedimentos atuais que realizam a AIA dentro desse processo de licenciamento.

PALAVRAS-CHAVES: Legislação Ambiental; Gestão Ambiental; Dano ambiental.

\section{EFFECTIVENESS OF THE ENVIRONMENTAL IMPACT ASSESSMENT IN BRAZIL}

\section{ABSTRACT}

The Environmental Impact Assessment (EIA) was established by the National Environmental Policy (Brazilian Federal Act 6938/1981) as one of the environmental management instruments for the preservation, improvement and maintenance of the environmental quality in Brazil. After more than 30 years of its prediction in the Brazilian legal system it is necessary to evaluate the results. This study examined the effectiveness of the EIA, i.e. if the instrument has reached the goal for which it was created. The research was exploratory outlined by bibliographic and documentary methods and based on the triangulation of three analytic dimensions: 1) primary objectives of the EIA;2) implementation and execution of the instrument; and 3 ) its current situation and prospects in Brazil. It was concluded that although it has provided positive effects the instrument has not adequately avoided the environmental damage arising from any developmental proposals that have the potential to do so as it was the primary goal. The reasons for this reduced effectiveness are explained by the lack of a legal and institutional framework to enable analyses of the environmental feasibility of proposals that are independent of the environmental licensing process and the weaknesses in current procedures that carry out the EIA in this licensing process.

KEYWORDS: Environmental Legislation; Environmental Management; Environmental Damage.
Revista Ibero-Americana de

Ciências Ambientais, Aquidabã, v.6, n.2, Jun, Jul, Ago, Set, Out, Nov 2015.

ISSN 2179-6858

SECTION: Articles

TOPIC: Legislação Ambiental

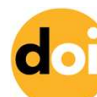

DOI: $10.6008 /$ SPC2179-6858.2015.002.0003

Thais Muniz Ottoni Santiago

Universidade Federal de Lavras, Brasil http://lattes.cnpq.br/3271387204496417 thaismottoni@gmail.com

José Luiz Pereira Rezende

Universidade Federal de Lavras, Brasil http://lattes.cnpq.br/7029395945890194 ilprezen@dcf.ufla.br

Luis Antônio Coimbra Borges Universidade Federal de Lavras, Brasil http://lattes.cnpq.br/2994935653109104 luis.borges@dcf.ufla.br

Aurélio Ferreira Borges

Instituto Federal de Rondônia, Brasil http://lattes.cnpq.br/400651011412055 aferreiraborges@gmail.com

Anderson Alves Santos

Instituto Federal de Minas Gerais, Brasil http://lattes.cnpq.br/7747265989770754 alvessanto@gmail.com

Received: 29/04/2015

Approved: 21/10/2015

Reviewed anonymously in the process of blind peer.

Referencing this:

SANTIAGO, T. M. O.; REZENDE, J. L. P.; BORGES, L. A. C.; BORGES, A. F.; SANTOS, A. A.. A eficácia da avaliação de impactos ambientais no Brasil. Revista IberoAmericana de Ciências Ambientais, Aquidabã, v.6, n.2, p.37-51, 2015. DOI:

http://dx.doi.org/10.6008/SPC21796858.2015 .002 .0003 


\section{INTRODUÇÃO}

A Política Nacional do Meio Ambiente (PNMA), instituída no Brasil por meio da Lei Federal n6938/81, possui a função de coordenar a aplicação das demais leis ambientais do país, oferecendo a elas uma coerência conceitual e, sobretudo, operacional. Seu corpo jurídico é estruturado em conceitos, princípios, objetivos e instrumentos de gestão ambiental, o que a organiza e a habilita à exercer esse papel norteador da política ambiental brasileira. Os instrumentos da PNMA desempenham papel chave por constituírem os mecanismos destinados a auxiliar ou levar a efeito os objetivos dessa política, que se resumem à: preservação, melhoria e recuperação da qualidade ambiental propícia à vida, visando a assegurar, no País, condições ao desenvolvimento socioeconômico, aos interesses da segurança nacional e à proteção da dignidade da vida humana (BRASIL, 1981).

Assim, o sucesso da PNMA está diretamente relacionado à eficácia de seus instrumentos. Dentre eles, se destaca a Avaliação de Impactos Ambientais (AIA) como um mecanismo diretamente destinado à prevenção do dano ao meio ambiente e, portanto, capaz de assegurar os padrões de qualidade ambiental requeridos pelo país. Muito se discute em relação ao conceito e a terminologia da AIA. Alguns autores se referem a ela como sinônimo de Estudo de Impacto Ambiental (EIA) (OLIVEIRA \& GUIMARÃES, 2004), outros a tratam como gênero do qual é espécie o EIA, considerando a possibilidade de se exigir diferentes tipos de estudos mais ou menos complexos no âmbito do licenciamento ambiental (MILARÉ, 2009; OLIVEIRA, 2005). Ainda há aqueles que incluem a possibilidade de aplicação do instrumento para além do processo de obtenção de licenças, isto é, também na formulação de políticas, planos e programas, assegurando um exame sistemático dos impactos ambientais deles decorrentes e a adoção de medidas adequadas de proteção do meio ambiente (EGLER, 2001; GHERSEL, 2007).

Essas diferentes percepções refletem o processo desordenado de regulamentação da AIA e reforçam a necessidade de se investigar se, após 30 anos de sua instituição, os objetivos primordiais do instrumento foram alcançados, ou ainda, se são asseguradas as condições necessárias para que sejam alcançados. Essa análise contribui, ainda, para a análise do sucesso da própria PNMA, dado o papel estratégico que seus instrumentos desempenham. Permite também a obtenção de subsídios para o aprimoramento da gestão ambiental brasileira, necessidade evidente e também já verificada por Antunes (2005) e Milaré (2009).

Constituiu, portanto, o objetivo geral desse trabalho a análise da eficácia da Avaliação de Impactos Ambientais, partindo da compreensão de eficaz como "aquilo que produz o efeito desejado" (FERREIRA, 2004, p.716). Foram objetivos específicos dessa pesquisa: elucidar a criação da AIA pela PNMA com a finalidade de identificar os objetivos pretendidos com a sua instituição; analisar as estratégias adotadas para a implementação deste instrumento e a evolução da sua aplicação na gestão dos recursos naturais brasileiros; e analisar a situação atual deste 
instrumento, tendo em vista a consecução dos objetivos esperados e as suas perspectivas futuras.

\section{METODOLOGIA}

Essa foi uma pesquisa qualitativa, de caráter analítico e exploratório, classificada de acordo com Gil (2010). É, portanto, um estudo que teve o propósito de preencher uma lacuna do conhecimento referente à eficácia da AIA como instrumento da PNMA, proporcionando uma visão geral do instrumento e a formulação de problemas mais precisos pesquisáveis em trabalhos posteriores. O delineamento desse trabalho se assemelha ao proposto por Corbin e Strauss (1990), no qual a coleta de informações, análise e teoria mantêm-se em relações recíprocas. A questão inicial é ampla e seu foco vai diminuindo durante o processo de pesquisa, na medida em que se descobre o que é ou não relevante durante esse processo, permitindo, assim, a possibilidade da descoberta.

A coleta de dados foi conduzida por métodos de pesquisa bibliográfica e documental, utilizando-se como fonte, respectivamente: livros, periódicos científicos, teses, dissertações e anais de encontros científicos nas áreas de Ciências Ambientais e Direito Ambiental, sendo as expressões de referência 'Avaliação de Impacto Ambiental', 'Política Nacional do Meio Ambiente' e 'Dano Ambiental'; e documentos jurídicos - como leis, resoluções e decretos - e institucionais mantidos em arquivos públicos de órgãos governamentais e outras orgnizações de meio ambiente. Adotou-se uma amostragem não-probabilística do tipo acessibilidade, normalmente aplicada a estudos exploratórios.

A análise dos dados foi fundamentada no método da triangulação de informações que consiste no estabelecimento de três dimensões analíticas (PEREIRA, 1991). Essas dimensões foram: objetivos primordiais da AIA; implementação e execução da AIA; e situação atual da AIA. Para cada uma dessas dimensões, segundo o proposto por Gil (2010), realizou-se leitura exploratória, seletiva, analítica e interpretativa, essa última com a finalidade de conferir significado mais amplo aos resultados obtidos relacionando-os com conhecimentos adquiridos pelo pesquisador. Essas dimensões foram trianguladas, confrontando-se as informações obtidas de forma que possibilitassem a obtenção de respostas ao problema proposto.

\section{DISCUSSÃO TEÓRICA}

Seguindo o delineamento metodológico dessa pesquisa e a fim de conferir raciocínio lógico ao leitor, os resultados são discutidos conforme as três dimensões de análise propostas.

\section{O Surgimento do instrumento 'Avaliação de Impactos Ambientais'}


Os fundamentos da avaliação ambiental foram estabelecidos nos Estados Unidos, em 1969, pelo National Environmental Policy Act - NEPA. Adotou-se a preparação de declarações de impacto ambiental, baseadas no conhecimento científico interdisciplinar, para subsidiar análises de viabilidade e prevenir o dano ao meio ambiente decorrente de projetos, políticas, planos e programas (GHERSEL, 2007). Como os conflitos entre o desenvolvimento econômico e suas consequências não eram limitados aos EUA, a concepção da avaliação ambiental difundiu-se mundialmente, sendo o momento, a forma e a abrangência de sua adoção determinadas pelas peculiaridades jurídicas e institucionais de cada país.

No Brasil, a primeira iniciativa a nível federal exigia, de forma bastante tímida, a elaboração de estudos ambientais como requisito à aprovação da delimitação e implantação de zonas estritamente industriais (BRASIL, 1980). Essa exigência ampliou-se e ganhou novo significado com a instituição da avaliação ambiental como instrumento da PNMA, fato influenciado pelo fortalecimento do movimento ambientalista no Brasil e pelo condicionamento de empréstimos internacionais para obras de infraestrutura, sobretudo hidrelétricas, à existência de um procedimento formal de avaliação ambiental no país.

O instrumento compôs o corpo jurídico da PNMA sob a terminologia 'Avaliação de Impactos Ambientais' que, segundo Ghersel (2007), ainda não estava consolidada à época. Essa terminologia firmou-se como um procedimento que integra aspectos ambientais no desenvolvimento e análise de projetos submetidos ao licenciamento ambiental, no entanto, como instrumento da PNMA, seu objetivo primordial ia além disso. Segundo Sánchez (2008, p.6), a PNMA adotou o modelo instituído pela NEPA, que exigia 'a avaliação prévia de impactos de quaisquer ações que pudessem afetar significativamente a qualidade do ambiente humano', referindo-se o termo 'ações' não somente a obras ou atividades, mas também a outras iniciativas governamentais como planos e programas. Não há, na Lei n6938/81, uma opção explícita do país por um modelo de avaliação ambiental restrita ao âmbito do licenciamento, mas, ao contrário, a 'AIA' e o 'Licenciamento e Revisão de Atividades Potencialmente Poluidoras' foram instituídos, pela PNMA, como dois instrumentos independentes e, a princípio, não relacionados. Portanto, o instrumento AIA (entenda-se Avaliação Ambiental), foi criado para subsidiar análises de viabilidade de quaisquer propostas de desenvolvimento do país, incluindo aquelas que ocorrem em nível de planejamento governamental, com a finalidade de prevenir o dano e manter a qualidade ambiental nos níveis requeridos pelo país.

\section{Estratégias para a Implementação e a Evolução da AIA}

A primeira estratégia adotada para aplicar o instrumento foi mediante o Decreto Federal $\mathrm{n}^{\circ}$ 88.351/83, torná-lo uma condição para a concessão de licenças ambientais pelas quais a Administração Pública autoriza a construção, instalação, ampliação e funcionamento de atividades consideradas efetiva ou potencialmente poluidoras, bem como dos empreendimentos capazes de 
causar degradação ambiental. A AIA tornou-se, então, um instrumento de seleção e adequação de atividades e empreendimentos que não comprometam os padrões de qualidade ambiental do país. Também foi destinado ao CONAMA a tarefa de fixar os critérios básicos segundo os quais a AIA seria exigida (BRASIL, 1983). O referido decreto foi revogado pelo Decreto $n^{\circ} 99.274 / 90$ que, no entanto, manteve as condições de vinculação entre licenciamento e AIA sem avançar na matéria e sem usufruir os demais potenciais do instrumento (BRASIL, 1990).

Ainda em resposta ao Decreto $n^{\circ} 88.351 / 83$, o CONAMA editou a Resolução $n^{0} 1 / 86$ que, considerando expressamente 'a necessidade de se estabelecerem as definições, as responsabilidades, os critérios básicos e as diretrizes gerais para uso e implementação da Avaliação de Impactos Ambientais como instrumento da Política Nacional do Meio Ambiente', acabou por regulamentar apenas a figura do Estudo de Impacto Ambiental - EIA - e seu respectivo Relatório de Impacto Ambiental - RIMA (BRASIL, 1986, grifo nosso). Segundo Milaré (2009), esse fato levou um grande número de pessoas, até mesmo estudiosos do assunto, a considerar que o instrumento de avaliação ambiental da PNMA se limitava a esse tipo de procedimento. O quadro permaneceu por alguns anos provocando grande atraso na utilização de demais métodos e oportunidades de prevenção do dano ambiental.

A Resolução n¹/86 definiu que dependeria da elaboração de EIA/RIMA, e de sua aprovação pelo órgão ambiental competente, o licenciamento de atividades 'modificadoras' do meio ambiente, arrolando uma lista exemplificativa daquelas que se encaixariam nessa classificação (BRASIL, 1986). No entanto, como não é possível conceber uma atividade antrópica que não altere o ambiente natural, a expressão 'atividades modificadoras do meio ambiente' significava que qualquer atividade proposta deveria ser precedida desse tipo de estudo, o que negava a utilização de modalidades mais simplificadas, e ainda assim suficientes, para projetos menos impactantes. O equívoco técnico foi corrigido pela Constituição Federal de 1988 que consolidou o EIA/RIMA como modalidade de AIA utilizada previamente à realização de obras ou atividades capazes de provocar 'significativa' degradação ambiental (BRASIL, 1988).

Para atividades de menor impacto sujeitas ao licenciamento, a Resolução CONAMA n 237/97 determinou que o órgão ambiental competente definisse o tipo de estudo mais adequado, tais como relatório ambiental e diagnóstico ambiental (BRASIL, 1997). Ela manteve o rol exemplificativo que a resolução anterior havia instituído para atividades exigentes de EIA/RIMA, mesmo diante de um novo critério para identificá-las, isto é, a significância do impacto. Consequentemente, há diferentes posicionamentos sobre o assunto: na doutrina jurídica tem prevalecido o entendimento de que essa significância é presumida e o EIA/RIMA deve ser realizado para as atividades listadas em 1986 (BENJAMIN, 1992; CAPELLI, 1992). Outros autores, porém, consideram que o órgão ambiental pode dispensá-los quando considerar que o impacto de tais atividades não é significativo (BUGALHO, 1999; GOUVÊA, 1998) ou, ainda, que deve exigi-los até que o empreendedor prove a insignificância do impacto (MILARÉ, 2009). 
Os procedimentos que constituem as avaliações ambientais de atividades menos impactantes vêm sendo definidos, de forma supletiva e complementar ao instituído pelo CONAMA e pelos próprios órgãos ambientais competentes. Já para a realização do EIA/RIMA, por se tratar de um mecanismo que ocupa maior espaço temporal no ordenamento jurídico brasileiro e por ser aplicado em situações que ameaçam significativamente a qualidade ambiental, existem diretrizes e procedimentos consolidados, determinadas pelo CONAMA. Isso faz desse tipo de estudo o principal mecanismo de aplicação da AIA no país. As etapas básicas para sua realização são apresentadas na Figura 1.

\begin{tabular}{|} 
Etapas do EIA/RIMA \\
$\begin{array}{l}\text { 1) Avaliação inicial das características do projeto e de sua área de localização: verificação da significância potencial do } \\
\text { impacto. }\end{array}$ \\
2) Estabelecimento do escopo do EIA por meio de termos de referência. \\
3) Elaboração do EIA, compreendendo: \\
3.1. Diagnóstico ambiental da área de influência do projeto. \\
3.2. Prognóstico dos prováveis impactos ambientais do projeto e de suas alternativas. \\
3.3. Medidas mitigadoras dos impactos negativos. \\
3.4. Programa de acompanhamento e monitoramento dos impactos decorrentes. \\
4) Preparação do RIMA contendo as conclusões do EIA e direcionado ao público. \\
5) Revisão da qualidade do EIA/RIMA. \\
6) Realização de audiências públicas. \\
7) Decisão quanto à aprovação da proposta. \\
8) Acompanhamento dos programas de compensação e monitoramento de impactos.
\end{tabular}

Figura 1: Procedimentos básicos do EIA/RIMA.

A elaboração do EIA e a preparação do RIMA ocorrem a expensas do empreendedor e devem ser conduzidas por uma equipe multidisciplinar legalmente habilitada, sendo ambos responsáveis, técnica e juridicamente, pelas informações apresentadas. As demais etapas são realizadas pelo órgão ambiental competente. Na fase de revisão do EIA/RIMA, ele pode decidir pela aprovação; complementação ou modificação; ou pela reprovação dos mesmos. As audiências públicas, que trazem à tona o interesse público para compor o documento, podem ser solicitadas pelo órgão ambiental, por entidade civil, pelo Ministério Público ou a pedido de 50 ou mais cidadãos. A decisão sobre a viabilidade da proposta pode resultar na aprovação total; parcial ou condicional do projeto; ou pela sua reprovação nas condições em que foi proposto. A decisão pode ainda ser questionada pelo Poder Judiciário mediante ação popular ou via ação civil pública. O acompanhamento dos programas de compensação e monitoramento de impactos tem a participação do empreendedor e o objetivo de assegurar a consecução das medidas mitigadoras (BRASIL 1986; 1987; 1997).

De modo geral, para que o EIA/RIMA influencie adequadamente a decisão do órgão ambiental e previna o dano ambiental, ele precisa: ser exigido no momento adequado, isto é, quando houver impacto ambiental significativo, justificando os custos e energia dispensados; produzir estudos ambientais de qualidade; considerar o interesse público; ser criteriosamente avaliado e de fato apropriado pelos agentes responsáveis pela decisão como um elemento de 
igual valor aos critérios técnicos e econômicos e promover o monitoramento dos impactos previstos, garantindo a qualidade ambiental desejada.

Como visto, também era objetivo primordial da avaliação ambiental instituída pela PNMA, a apropriação de um processo mais amplo de análise - atualmente denominado Avaliação Ambiental Estratégica ( $A A E)$ - que integrasse variáveis ambientais em etapas de planejamento independentes e anteriores à obtenção de licenças ambientais. No entanto, ainda não há, no Brasil, um quadro legal que exija e possibilite a realização desse processo. A atribuição legal dos órgãos ambientais, por exemplo, só os permite exigir a avaliação ambiental na oportunidade de concessão de licenças a projetos, o que não condiz com a natureza da AAE. Assim, a utilização da avaliação ambiental, no país, é limitada ao processo de licenciamento de obras e atividades capazes de causar degradação ambiental.

A Lei Complementar n¹40/2011 afirma que o licenciamento ambiental - e a AIA - deve ser realizado por um único ente federativo, ressaltando a necessidade de cooperação entre eles. Identifica-se o orgão habilitado para licenciar de acordo com a área de influência direta do impacto ambiental: à União cabem as ações de maior escala, devidamente descritas na lei; aos municípios, aquelas definidas por resoluções dos conselhos estaduais de meio ambiente - aos quais cabe a conceituação de impacto ambiental local - e, aos estados, destinou-se a competência residual (BRASIL, 2011a).

\section{Situação Atual do Instrumento de Avaliação Ambiental da PNMA}

As seções a seguir apresentam a situação atual do instrumento de avaliação ambiental instituído pela PNMA considerando as facetas que o mesmo acabou por assumir em função do seu histórico de construção no Brasil, isto é, enquanto Avaliação de Impactos Ambientais (AIA) e Avaliação Ambiental Estratégica (AAE).

\section{A Avaliação de Impactos Ambientais}

Questões sobre a situação atual da avaliação ambiental, no âmbito do licenciamento, podem ser mais seguramente abordadas em relação ao EIA/RIMA - para o qual existem diretrizes federais que definem os procedimentos de consecução. A seleção desse tipo de estudo se dá pela previsão de que "significativo" impacto ambiental decorra da obra ou atividade em análise. No entanto, não há um critério capaz de precisar o que é impacto significativo e tampouco há como prever, com segurança, que ele decorra da concretização da proposta - o impacto que parece ser insignificante torna-se profundamente significante se, por exemplo, romper o ponto de saturação ambiental da área. Buscando uma salda para a questão, o Decreto n99.274/90 atribuiu ao CONAMA a tarefa de estabelecer critérios que identificassem áreas críticas, saturadas ou em vias de saturação, capazes de indicar um possível impacto significativo caso obras e atividades se 
estabelecessem nessas áreas. Essa atribuição ainda se mantém vigente pelo Decreto $n^{\circ}$ 3.942/2001, mas sem resultados, já que o referido órgão, aparentemente, ainda não trabalhou a questão como esperado (BRASIL, 1990; 2001).

A falta de critérios precisos que identifiquem a necessidade de EIA/RIMA gera falta de uniformidade na aplicação do instrumento e abre possibilidade tanto para que esse seja exigido desnecessariamente, podendo inviabilizar obras importantes devido ao seu alto custo, quanto para que haja a sua dispensa indevida, negligenciando graves impactos decorrentes do projeto. Essa última situação, aliás, tem sido muito comum no Brasil (LOVATO, 2008). Também têm sido comumente reportados problemas nos termos de referência que definem o escopo e são diretamente responsáveis pela qualidade dos estudos apresentados. Esses termos devem ser adequados às características próprias do projeto e da sua localização, mas, no entanto, no caso específico de projetos hidrelétricos, verificou-se que o mesmo termo de referência tem sido aplicado a diferentes biomas e a diferentes desenhos de empreendimentos (BANCO MUNDIAL, 2008).

Além disso, a qualidade de termos de referência tem sido comprometida pela pouca participação de órgãos sociais no processo de sua elaboração. Recentemente foi estabelecido pela Portaria Interministerial $n^{\circ} 419 / 2011$ um prazo para que a Fundação Nacional do Índio (FUNAI), a Fundação Cultural Palmares (FCP), o Instituto do Patrimônio Histórico e Artístico Nacional (IPHAN) e o Ministério da Saúde enviem termos de referência específicos contendo as considerações que julgarem necessárias aos processos de licenciamento ambiental federal (BRASIL, 2011b). Expirado o prazo estabelecido, o termo de referência elaborado pelo IBAMA será consolidado, dando prosseguimento ao licenciamento independentemente da capacidade desses órgãos e entidades atenderem-no. Não se discute aqui a necessidade de reduzir o tempo gasto com a burocracia do processo, mas a ausência de esforços destinados à efetiva participação desses órgãos e entidades. Se por um lado eles devem ser estimulados a produzir em tempo hábil, por outro, devem ser fornecidas infraestrutura e capacitação técnica para que a participação dos mesmos, que é de interesse público, possa ser efetivada.

A abrangência de EIAs no licenciamento federal de ferrovias, dutos, linhas de transmissão, rodovias, portos, mineração, termoelétrica e aproveitamentos hidrelétricos que possam causar danos em terras indígenas ou quilombolas também foi fixada nessa portaria. Estabeleceu-se, por tipologia de empreendimento e de forma diferenciada para a região da Amazônia Legal, uma quilometragem que indica a extensão do impacto gerado a partir da localização do empreendimento que se pretende realizar. Presume-se que a área além dessa referência não será impactada e, portanto, não precisa ser objeto de EIA. Até então, a extensão do impacto ambiental era definida em laudos e pareceres que até envolviam vistorias técnicas (BRASIL, 2008) - o que parece ser mais adequado já que essa dificilmente obedece a quilometragens prédefinidas. Aparentemente, buscou-se agilizar o proccesso de AIA sem que a qualidade dos estudos apresentados fosse assegurada. 
A má qualidade de EIA também tem como causa a deficiência de termos de referências e até mesmo a negligência ao que propõem esses termos (BANCO MUNDIAL, 2008; LIMA; MAGRINI, 2010; VULCANIS, 2010). Há também falta de informação técnica-científica sobre o ambiente físico e biológico, principalmente em áreas com populações relativamente pequenas, que criam trabalho e custo adicionais para o investidor na construção e no processamento de uma grande quantidade de dados de campo (BANCO MUNDIAL, 2008). Por fim, há uma generalizada ausência de prognósticos sobre os impactos da utilização de recursos naturais não renováveis e sobre a disponibilidade futura desses recursos (MACHADO \& VILANI, 2010).

Em relação aos aspectos sociais, Agra Filho (2008) constata ElAs com diagnósticos precários e reducionistas, prognósticos omissos e tendenciosos, ausência de programas de monitoramento para os impactos sociais gerados e medidas mitigadoras dotadas da ideia de socialização do ônus e direcionadas ao Poder Público. Mas, também há afirmações sobre a obrigação atribuída ao investidor, em função das mazelas pré-existentes, de resolver impactos sociais que não têm relação com os impactos da obra em si (BANCO MUNDIAL, 2008). Esse repasse de responsabilidades entre o empreendedor e o governo enseja a definição de regras claras de compensação social.

De mandeira geral, os RIMAs gerados a partir de EIAs não possuem a qualidade reducionistas em relação a grandes passivos ambientais para os quais não há medidas mitigatórias ou compensatórias (COSTA et al., 2010) - e o conteúdo metodológico prescrito pela Resolução CONAMA n 01/86. Além de sua redação em linguagem inapropriada, a disposição desses documentos ao acesso público é insatisfatória para a adequada apreciação pelos diversos interessados. Isso impede que a sociedade construa questionamentos mais elaborados sobre a viabilidade do projeto e fragilizam o debate em audiências públicas. A questão é ainda agravada pelo fato de que raramente as ideias levantadas são, de fato, consideradas (AGRA FILHO, 2008; SIQUEIRA, 2008).

O vínculo direto entre quem empreende e quem elabora esses estudos tem de fato contribuído para um direcionamento indevido dos mesmos, ensejando a comercialização de EIAs/RIMAs tendenciosos e facilitadores da concessão de licenças (VULCANIS, 2010). Por outro lado, esse vínculo minimiza os custos depreendidos da elaboração dos estudos, especialmente no caso de empresas e entidades públicas que já possuem profissionais técnicos em seus quadros capacitados para tanto (MILARÉ, 2009). A neutralidade desejada na consecução do EIA/RIMA deve ser, portanto, garantida pela contra-equipe governamental responsável por examiná-lo. Contudo, esse é mais um ponto frágil do processo. Diversos autores afirmam que a avaliação do conteúdo de EIA/RIMAs, pelos órgãos ambientais, tem sido inconsistente devido à falta de treinamento e de especialização do quadro de pessoal em certas áreas do conhecimento, sobretudo na área social (BANCO MUNDIAL, 2008; LIMA \& MAGRINI, 2010).

A Portaria Interministerial $n^{\circ} 419 / 2011$, parecer agravar essa carência ao determinar o andamento de processos de licenciamento federal quando órgãos e entidades sociais convocados 
a manifestar sobre os EIA/RIMAs apresentados, não forem capazes de atender ao prazo estipulado (BRASIL, 2011b). Assim, o processo deve seguir a despeito das contribuições que tais órgãos, dadas as especialidades que possuem, poderiam oferecer na prevenção ou mitigação dos potenciais impactos sociais, e, sem que haja o questionamento sobre os motivos do atraso, muitas vezes, relacionado à falta de estruturas suficientes para dar conta do volume e da complexidade de obras que estão sendo licenciadas. Ainda quando são detectados EIA/RIMAs deficientes pelo órgão ambiental, são raras as situações em que os técnicos que elaboraram os estudos são responsabilizados ou em que esses estudos são reprovados por falta de qualidade (VULCANIS, 2010). Assim, instaura-se um sentimento de impunidade que sustenta a constante elaboração de EIA/RIMAs tendenciosos.

As audiências públicas constituiriam uma importante ferramenta capaz de adequar o conteúdo dos estudos apresentados pelo empreendedor ao interesse da coletividade se fossem produtivas - o que não é o caso (AGRA FILHO, 2008; BANCO MUNDIAL, 2008; SIQUEIRA, 2008; VULCANIS, 2010). Como são o único canal de interlocução durante o processo do licenciamento, essas audiências tornam-se palco do afloramento de passivos socioambientais que, muitas vezes, têm pouca relação com o licenciamento do empreendimento em si. Essa situação não ocorre em outros países que contam com mecanismos mais amplos de participação pública, como por exemplo, as audiências prévias realizadas antes do início da execução do EIA e que contribuem para o estabelecimento de seus termos de referência (SÁNCHEZ, 1995).

No Brasil, o quadro é agravado pela omissão do governo como mediador no processo de negociação e até mesmo pela sua tendenciosidade à viabilização de licenças isentas de restrições (AGRA FILHO, 2008). Como os conflitos raramente são resolvidos, eles tendem a proliferar ao longo do processo, causando uma intensa demanda judicial para a proteção do meio ambiente. Para o Banco Mundial (2008), a excessiva interferência do Ministério Público nas etapas de AIA é a causa da falta de previsibilidade e da tempestividade do licenciamento ambiental. No entanto, a apatia desse órgão, provavelmente, teria trazido resultados desastrosos para a qualidade ambiental do país. Essa excessiva interferência parece indicar o quão insuficiente é a aplicação da AIA e evidenciar a importância do papel do Ministério Público na busca por soluções imediatas, enquanto há falhas em todo o processo de avaliação ambiental.

As disparidades entre a indicação e a efetiva implantação e monitoramento das medidas mitigadoras determinadas em EIAs finalizam o quadro de aplicação da AIA no Brasil (PRADO et al., 2004). Mas, ainda que esse seja precário, é inegável que o instrumento da PNMA promoveu a inclusão da variável ambiental nas análises de viabilidade de projetos e tem efetivamente influenciado as decisões sobre a execução dos mesmos. Ainda que apropriado como mera formalidade e sem a qualidade esperada, a simples existência de um procedimento que proclama a prevenção ao dano ambiental previamente à execução de uma obra ou atividade, já é um resultado positivo. A AIA promove o debate público sobre as consequências ambientais das atividades antrópicas; incentiva a organização da comunidade pela sua inclusão no processo 
decisório; busca concretizar, a um só tempo, o direito do cidadão ao ambiente ecologicamente equilibrado e o seu dever de preservá-lo; modifica propostas para aumentar a aceitabilidade do projeto no momento do licenciamento; interrompe a concepção de projetos por razão de sua inviabilidade ambiental; prevê medidas mitigadoras dos impactos negativos e incentiva pesquisas e tecnologias menos danosas ao meio ambiente.

Contudo, sendo destinada à previsão de impactos locais, a AIA não se presta a considerar impactos cumulativos (decorrente dos efeitos somados de projetos já instalados), sinergéticos (quando os impactos de diferentes projetos excedem a mera soma de seus impactos individuais), ancilares (nos casos em que um projeto estimula o desenvolvimento de outros) e globais (decorrentes, por exemplo, da emissão de gases do efeito estufa) (EGLER, 2001). Para que a AIA obtenha sucesso na prevenção do dano ambiental e considere adequadamente as alternativas tecnológicas e de localização de obras e atividades sujeitas ao licenciamento, evitando desperdício de tempo e recurso, é preciso que essas sejam decorrentes de um planejamento estratégico de desenvolvimento que utilize ferramentas capazes de analisar e prevenir, previamente, os potenciais impactos indiretos das alternativas de desenvolvimento.

\section{Avaliação Ambiental Estratégica}

A utilização da AAE para a análise de viabilidade de políticas, programas e planos, ocorre em um momento onde é possível traçar a melhor estratégia diante de um leque de alternativas de desenvolvimento e com maior flexibilidade em relação ao tempo gasto quando comparado à AIA. Assim, é possível a participação de diferentes atores e a utilização de diferentes e mais adequadas metodologias de previsão de impactos indiretos. Além disso, a AAE não só atua como um procedimento de integração das dimensões econômicas, sociais e ambientais de uma proposta, como tamém de articulação entre diferentes propostas, permitindo ao país alcançar a sustentabilidade de seu desenvolvimento.

Embora tenham sido previstas ao mesmo tempo pelo NEPA, em 1970, somente depois que a prática de avaliação ambiental de empreendimentos tornou-se razoavelmente consolidada, a partir da década de 1990, é que os critérios e metodologias de avaliação ambiental de propostas de desenvolvimento se popularizaram e se firmaram como um campo de atividades destacado. Esse vem se expandindo internacionalmente principalmente na Europa, onde se apresenta institucionalizada e objeto de leis (GHERSEL, 2007; SÁNCHEZ, 2008). Por outro lado, enquanto prevalece a inércia da ausência de um quadro legal para a utilização da AAE no Brasil, políticas, planos e programas continuam sendo incapazes de evitar impactos socioambientais significativamente adversos, tais como os relatos por Sánchez et al. (1994) e Vilani e Machado (2010). Esses últimos afirmam que o Programa de Aceleração do Crescimento (PAC) foi elaborado e implementado sem que qualquer medida social e ambiental fosse considerada (VILANI \& MACHADO, 2010). 
Embora Teixeira (2008) considere que algumas iniciativas 'voluntárias' de utilização da AAE tenha sido desenvolvidas no país - tais como, na elaboração do Plano Indicativo 2003-2012 da Eletrobrás e o Rodoanel Metropolitano de São Paulo - alguns estudos mostram que, em geral, tais iniciativas não apresentam as características típicas de AAE, tratando-se, na verdade, de estudos de impacto ambiental com abrangência geográfica estendida, seguindo modelos prontos fornecidos por Agências Multilateriais de Desenvolvimento que não se adequam à realidade brasileira (PELLIN et al., 2011; SILVA, 2010).

Outras inciativas partiram do Tribunal de Contas da União, por meio do Acórdão 464/2004 e outros que o seguiram, recomendando a ampliação da divulgação da AAE; a oferta de capacitação de gestores; o desenvolvimento de metodologias com a participação de diversos segmentos da sociedade; e a análise por parte do governo sobre a oportunidade de adoção da AAE no processo de elaboração dos planos plurianuais (PPAs) e de políticas, planos e programas setoriais (BRASIL, 2004). Os Ministérios do Planejamento, Meio Ambiente e Transportes, por sua vez, promoveram ações para articular um grupo de trabalho para discussão e elaboração de um guia com propostas práticas para a AAE no contexto brasileiro. Destaca-se o estudo elaborado pelo Ministério do Meio Ambiente, sugerindo oito etapas sequenciais báscas para a condução de um processo de AAE no Brasil (BRASIL, 2002; EGLER, 2001; SÁNCHEZ, 2008).

Apenas algumas propostas legislativas se destinaram à inclusão da AAE na PNMA, com destaque para os Projetos de Lei n²072/03, n³729/04 e n³957/2004, que, no entanto, encontram-se arquivados no Congresso Nacional. Ainda faz-se necessário o estabelecimento de legislação federal que exija e permita a realização da $A A E$, legitimando seus condutores, viabilizando a articulação institucional necessária, as ações vitais para a participação popular no processo de tomada de decisão e a alocação de recursos humanos e financeiros. Além disso, é imprescindível que tal marco legal desvincule a AAE do processo de licenciamento ambiental, uma vez que se não se trata de submeter políticas, planos e programas à AAE para que sejam aprovados, mas sim de usá-la para formular tais políticas, programas e planos. Esse é um processo delicado que passa pela polêmica definição de um conjunto de princípios e procedimentos que caracterize a $A A E$ a ser aplicada no Brasil, tomando o cuidado do não transformá-la em um procedimento extremamente moroso ou burocrático (SÁNCHEZ, 2008; SILVA, 2010).

Ainda que a $A A E$ seja requerida legalmente, sua apropriação depende de um nível significativo de maturidade institucional e vontade política para que núcleos de pensamento ambiental crítico e proativo sejam estabelecidos em todos aqueles órgãos ou repartições da Administração Pública que têm ou poderão ter interfaces com a qualidade do meio ambiente (MILARÉ, 2009). E ainda, que haja um vínculo estável e bem definido entre esses núcleos. À esse gargalo, inerente ao contexto político brasileiro, soma-se a falta de recursos (informação, especialista, financeiro), de clareza e envolvimento público no momento da formulação das das políticas governamentais. Enquanto não há uma posição proativa do governo para superar esses 
obstáculos, a ausência de AAE segue limitando o sucesso da AIA de projetos específicos, subjugando o instrumento de Avaliação Ambiental estabelecido pela PNMA e reduzindo o alcance dos objetivos da própria política.

\section{CONCLUSÕES}

Após mais de trinta anos da sua instituição como instrumento da PNMA, a Avaliação Ambiental ainda não foi adequadamente apropriada como um mecanismo de prevenção do dano ambiental decorrente de políticas, planos, programas e de projetos específicos, como era o objetivo. Sua aplicação é insuficiente tanto por ser restrita ao licenciamento ambiental - não havendo um quadro institucional que permita a sua utilização independentemente da obtenção de licenças e em nível mais amplo de planejamento - quanto pelas deficiências de seus métodos. Esses, por sua vez: não fornecem informações de qualidade para as análises de viabilidade ambiental; não solucionam conflitos envolvidos na realização do projeto e não resultam em efetiva mitigação do impacto adverso. Como não atingiu os resultados esperados com a sua criação, é possível afirmar que o instrumento não tem sido eficaz no Brasil.

Ainda assim, a comparação entre o cenário atual e aquele anterior à institucionalização da Avaliação Ambiental pela PNMA mostra que muitos benefícios já foram obtidos. Hoje, há um espaço dentro do processo de análise da viabilidade de empreendimentos destinado à discussão dos impactos ambientais decorrentes dos mesmos, o que antes não ocorria. E esse espaço, mesmo que não tanto quanto esperado, tem certamente provocado mudanças no comportamento de agentes responsáveis pela decisão de concretizar ou não a proposta desenvolvimentista no sentido da mitigação de impactos negativos.

Considerando que o país ainda possui grandes áreas naturais remanescentes; uma concentração de atividades primárias particularmente vulneráveis à degradação ambiental; que há baixa consistência nas alternativas de desenvolvimento selecionadas; e que existem compromissos nacionais e internacionais assumidos para a sustentabilidade ambiental, é evidente a necessidade do país de buscar a eficácia de seu instrumento de avaliação ambiental. $E$ isso passa, necessariamente, pela institucionalização da AAE e pela melhoria das práticas de AIA.

\section{REFERÊNCIAS}

AGRA FILHO, S. S.. Conflitos ambientais e os instrumentos da Política Nacional de Meio Ambiente. Revista eGesta. São Paulo, v.4, n.2, p.127-140, 2008.

ANTUNES, P. B.. Política Nacional do Meio Ambiente PNMA: comentários à Lei 6.938, de 31 de agosto de 1981. Rio de Janeiro: Lumen Juris, 2005.

BANCO MUNDIAL. Licenciamento ambiental de empreendimentos hidrelétricos no Brasil: uma contribuição para o debate. Washington: Banco Mundial, 2008.

BENJAMIN, A. H. V.. Os princípios do estudo de impacto ambiental como limites da discricionariedade administrativa. Revista Forense. Rio de Janeiro, v.317, p.25-45, 1992. 
BRASIL. Constituição da República Federativa do Brasil. Brasília: Senado, 1988.

BRASIL. Decreto Federal $n^{\circ} \mathbf{8 8 . 3 5 1}$, de 1 de Junho de 1983. Regulamenta a Lei $n^{\circ} 6.938$, de 31 de agosto de 1981, e a Lei $n^{\circ}$ 6.902, de 27 de Abril de 1981, que dispõem, respectivamente, sobre a Política Nacional do Meio Ambiente e sobre a criação de Estações Ecológicas e Áreas de Proteção Ambiental. Brasília: MMA, 3 jun 1983.

BRASIL. Decreto Federal $n^{\circ} 99.274$, de 6 de Junho de 1990. Regulamenta a Lei $n^{\circ} 6.902$, de 27 de abril de 1981, e a Lei $n^{\circ} 6.938$, de 31 de agosto de 1981, que dispõem, respectivamente sobre a criação de Estações Ecológicas e Áreas de Proteção Ambiental e sobre a Política Nacional do Meio Ambiente, e dá outras providências. Brasília: DOU, 7 jun 1990.

BRASIL. Decreto Federal $n^{\circ} 3.942$ de 27 de Setembro de 2001. Dá nova redação aos arts. $4^{\circ}, 5^{\circ}, 6^{\circ}, 7^{\circ}$, 10 e 11 do Decreto no 99.274, de 6 de junho de 1990. Brasília: DOU, 28 set. 2001.

BRASIL. Instituto Brasileiro do Meio Ambiente e dos Recursos Naturais Renováveis. Instrução Normativa $\mathrm{n}^{\circ} 184$, de 17 de julho de 2008. Estabelece procedimentos para o licenciamento ambiental federal. Brasília: DOU, 18 jul 2008.

BRASIL. Lei Complementar n¹40, de 8 de Dezembro de 2011a. Fixa normas, nos termos dos incisos III, VI e VII do caput e do parágrafo único do art. 23 da Constituição Federal, para a cooperação entre a União, os Estados, o Distrito Federal e os Municípios nas ações administrativas decorrentes do exercício da competência comum relativas à proteção das paisagens naturais notáveis, à proteção do meio ambiente, ao combate à poluição em qualquer de suas formas e à preservação das florestas, da fauna e da flora; e altera a Lei no 6.938, de 31 de agosto de 1981. Brasília: DOU, 9 dez 2011.

BRASIL. Lei Federal $n^{\circ} \mathbf{6 . 8 0 3}$, de 2 de julho de 1980. Dispõe sobre as diretrizes básicas para o zoneamento industrial nas áreas críticas de poluição. Brasília: DOU, 3 set 1980.

BRASIL. Lei Federal $n^{\circ} 6.938$, de 31 de agosto de 1981. Dispõe sobre a Política Nacional de Meio Ambiente, seus fins e mecanismos de formulação e aplicação. Brasília: DOU, 2 set 1981.

BRASIL. Ministério do Meio Ambiente. Avaliação ambiental estratégica. Brasília: DOU, 2002.

BRASIL. Portaria Interministerial $n^{\circ} 419$, de 26 de outubro de 2011b. Regulamenta a atuação dos órgãos e entidades da Administração Pública Federal, envolvidos no licenciamento ambiental de que trata o art. 14 da Lei $n^{\circ} 11.516$ de 28 de agosto de 2007. Brasília: DOU, 28 out 2011.

BRASIL. Resolução CONAMA n 01, de 23 de janeiro de 1986. Dispõe sobre critérios básicos e diretrizes gerais para a avaliação de impacto ambiental. Brasília: DOU, 17 fev 1986.

BRASIL. Resolução CONAMA nº 09, de 3 de dezembro de 1987. Dispõe sobre a realização de Audiências Públicas no processo de licenciamento ambiental. Brasília: DOU, 05 jul 1990.

BRASIL. Resolução CONAMA n 237, de 19 de dezembro de 1997. Dispõe sobre a revisão e complementação dos procedimentos e critérios utilizados para o licenciamento ambiental. Brasília: DOU, 22 dez 1997.

BRASIL. Tribunal de Contas da União. Acórdão n464 de 28 de Abril de 2004. Análise da aplicabilidade, pelo Governo Federal, do instrumento Avaliação Ambiental Estratégica. Brasília: DOU, 28 abr 2004.

BUGALHO, J. N. R.. Estudo prévio de impacto ambiental. Revista de Direito Ambiental, São Paulo, v.15, p. 18-33, 1999.

CAPELLI, S.. O estudo de impacto ambiental na realidade Brasileira. Revista do Ministério Público do Estado do Rio Grande do Sul, Porto Alegre, v.1, n.27, p.45-60, 1992.

CORBIN, J.; STRAUSS, A.. Grounded Theory Research: Procedures, Canons, and Evaluative Criteria. Qualitative Sociology. v.13, n.1, 1990.

COSTA, G. B.; LOCKS, R.; MATOS, D. S.. Análise do relatório do impacto ambiental das usinas hidrelétricas no rio madeira no município de Porto Velho (RO). In: ENCONTRO NACIONAL DA ANPPAS. 5. Anais. Florianópolis: ANPPAS, 2010. 
EGLER, P. C. G.. Perspectivas de uso no Brasil do processo de avaliação ambiental estratégica. Parcerias Estratégicas. Brasília, v.6, n.11, p.175-190, 2001.

FERREIRA, A. B. H.. Novo dicionário Aurélio da língua portuguesa. 3 ed. Curitiba: Positivo, 2004.

GHERSEL, E.. A avaliação ambiental estratégica e a política nacional do meio ambiente. Belo Horizonte: Del Rey, 2007.

GIL, A. C.. Como elaborar projetos de pesquisa. 5 ed. São Paulo: Atlas, 2010.

GOUVÊA, Y. M. G.. A interpretação do art. $2^{\circ}$ da Resolução CONAMA n01/86: avaliação de impacto ambiental. São Paulo: Secretaria do Meio Ambiente, 1998.

LIMA, L. H.; MAGRINI, A.. The Brazilian audit tribunal's role in improving the federal environmental licensing process. Environmental Impact Assessment Review. New York, v.30, n.2, p.108-115, 2010.

LOVATO, M. L.. O poder discricionário da administração pública na política nacional do meio ambiente: o problema do licenciamento ambiental. Revista de Discurso Jurídico. Campo Mourão, v.4, n.1, p.124-140, 2008.

MACHADO, C. J. S.; VILANI, R. M.. Aspectos conceituais do licenciamento ambiental na conservação de recursos naturais não renováveis. Revista de Informação Legislativa. Brasília, v.47, n.188, p.143-152, 2010.

MILARÉ, E.. Direito do ambiente: a gestão ambiental em foco: doutrina, jurisprudência, glossário. 6 ed. São Paulo: Revista dos Tribunais, 2009.

OLIVEIRA, A. I. A.. Introdução à legislação ambiental Brasileira e licenciamento ambiental. Rio de Janeiro: Lumen Juris, 2005.

OLIVEIRA, F. P. M.; GUIMARÃES, F. R.. Direito, meio ambiente e cidadania. São Paulo: Madras, 2004.

PELLIN, A.; LEMOS, C. C.; TACHARD, A.; OLIVEIRA, I. S. D.; SOUZA, M. P.. Avaliação Ambiental Estratégica no Brasil: considerações a respeito do papel das agências multilaterais de desenvolvimento. Revista Engenharia Sanitária Ambiental. v.16, n.1, p.27-36, 2011.

PEREIRA, J. R.. Movimento associativista rural e igreja em São Domingos do Prata (MG). Dissertação (Mestrado em Administração) - Universidade Federal de Lavras, Minas Gerais, 1991.

PRADO FILHO, J. F.; SOUZA, M. P.. O licenciamento ambiental da mineração no quadrilátero ferrífero de Minas Gerais: uma análise da implementação de medidas de controle ambiental formuladas em EIAS/RIMAS. Engenharia Sanitária e Ambiental. Rio de Janeiro, v.9, n.4, p.44-48, 2004.

SÁNCHEZ, L. E.. Avaliação ambiental estratégica e sua aplicação no Brasil. São Paulo: Instituto de Estudos Avançados, 2008.

SÁNCHEZ, L. E.. O processo de avaliação de impacto ambiental, seus papéis e funções. In: LIMA, A. L. B. R.; TEIXEIRA, H. R.; SÁNCHEZ, L. E. (Org.). A efetividade da avaliação de impacto ambiental no Estado de São Paulo: uma análise a partir de estudos de caso. São Paulo: Secretaria do Meio Ambiente, 1995.

SÁNCHEZ, L. E.; HENNIES, W. T.; ESTON, S. M.; MENEZES, C. B.. Cumulative impacts and environmental liabilities in the Santa Catarina Coalfield in Southern Brazil. In: INTERNATIONAL SIMPOSIUM ENVIRONMENTAL ISSUES AND WASTE MANAGEMENT IN ENERGY AND MINERAL INDUSTRIES. 3.

Anais. Perth: ICE, 1994.

SILVA, F. R.. Avaliação ambiental estratégica como instrumento de promoção do desenvolvimento sustentável. Revista de Direitos Fundamentais e Democracia. São Paulo, v.8, n.8, p.301-329, 2010.

SIQUEIRA, L. C.. Política ambiental para quem? Ambiente \& Sociedade. São Paulo, v.11, n.2, p.425-437, 2008. 
TEIXEIRA, I. M. V.. O uso da avaliação ambiental estratégica no planejamento da oferta de blocos para exploração e produção de petróleo e gás no Brasil: uma proposta. Tese (Doutorado em Ciências em Planejamento Estratégico) - Universidade Federal do Rio de Janeiro, Rio de Janeiro, 2008.

VILANI, R. M.; MACHADO, C. J. S.. Energia e meio ambiente no Programa de Aceleração do Crescimento (PAC): uma análise crítica. In: ENCONTRO NACIONAL DA ANPPAS. 4. Anais. Brasília: ANPPAS, 2008.

VULCANIS, A.. Os problemas do licenciamento ambiental e a reforma do instrumento. In: CONGRESSO INTERNACIONAL DE DIREITO AMBIENTAL. 14. Anais. São Paulo: Imprensa Oficial do Estado de São Paulo, 2010. 